\title{
Formas de tratamento no português angolano: análise sobre o uso do "tu" e do "você" em entrevistas gravadas
}

\author{
Maike da Silva Pereira; Silvana Silva de Farias Araujo ${ }^{2}$ \\ 1. Bolsista FAPESB, Graduando em Letras com Inglês, Universidade Estadual de Feira de Santana, e-mail: \\ maike.js@hotmail.com \\ 2. 2. Orientadora, Departamento de Letras e Artes, Universidade Estadual de Feira de Santana, e-mail: \\ silvana.uefs.2014@gmail.com
}

PALAVRAS-CHAVE: Sociolinguística; Português Angolano; $2^{\mathrm{a}}$ pessoa do singular

\section{INTRODUÇÃO}

Com os avanços dos estudos linguísticos no país, questões que averiguam o uso real da língua contrapondo-o com o teor prescritivo presente em gramáticas tem sido constantemente debatidas. Visando compreender e analisar as variações na língua falada, os estudos linguísticos têm diminuindo o abismo entre a língua real e o padrão ideal de língua, que consiste na língua dita "culta" presente em gramáticas normativas. (BAGNO, 2001). A forma pronominal de $2^{\mathrm{a}}$ pessoa tem sido amplamente discutida, retomando a ideia do abismo que há entre o falante e o ensino prescritivo da língua apresentado anteriormente, constatamos em gramáticas tradicionais como único uso aceitável para $2^{\mathrm{a}}$ pessoa os pronomes $t u$ e vós - singular e plural, respectivamente. Sendo indispensável para além do uso, a concordância verbal e nominal padrão do pronome com o verbo e substantivo. Tal configuração soa arcaica, pois podemos observar no nosso cotidiano o quão comum é para o falante a substituição do pronome $t u$ pelo você, o que perante a definição das gramáticas normativas é considerado erroneamente como incorreto. Ressalta-se que, ao utilizar o você, o falante realiza a concordância verbal com a terceira pessoa, coloquialmente frases deste tipo são comumente observadas; é a partir destes questionamentos que esta pesquisa investigou a variação no uso das formas pronominais (você, $t u$ ) no português angolano (PA), comparando com pesquisas realizadas por outros pesquisadores que investigam o mesmo fenômeno no português brasileiro.

\section{MATERIAL E MÉTODOS OU METODOLOGIA (ou equivalente)}

Este estudo foi realizado de acordo com o modelo teórico-metodológico da Sociolinguística Variacionista, que tem como base os estudos de Labov (2008[1972]), e busca compreender os contextos que condicionam o uso das variantes $t u$ e você como forma de tratamento no português angolano (PA). A Sociolinguística Variacionista tem como objetivo analisar a variação linguística em determinada comunidade de fala.

Adotando esse modelo para a realização dessa análise, contamos com um corpus com entrevistas DID (Diálogo entre Documentador e Informante) de informantes angolanos. A partir da minuciosa audição dessas entrevistas, seguimos para a etapa de revisão pois as entrevistas foram transcritas em pesquisas anteriores; essa etapa é extremamente importante, pois tem como intuito revisar os arquivos transcritos para que a transcrição feita pelos bolsistas estejam o mais fiel possível às entrevistas. Após a fase de revisão e tendo como embasamento a revisão da literatura, os dados foram levantados para que em sequência fossem codificados, tratados estatisticamente por meio da ferramenta computacional GoldVarbX (SANKOFF; TAGLIAMONTE; SMITH, 2005) e, por fim, devidamente analisados. 


\section{RESULTADOS E/OU DISCUSSÃO (ou Análise e discussão dos resultados)}

Foram encontradas 253 ocorrências de uso da segunda pessoa do singular no corpus. Destas 253 ocorrências totalizadas, 240 foram do uso do você e 12 foram do uso do $t u$. O resultado final apontou para $89 \%$ de concordância verbal padrão com o uso do tu e do você, ou seja, 225 dos casos - e apenas $11 \%$ de concordância verbal não padrão, o equivalente a 28 ocorrências. Apenas uma ocorrência trouxe um outro pronome "vocemece".

\begin{tabular}{|l|c|c|}
\hline & Concordância padrão & Concordância não-padrão \\
\hline $\begin{array}{l}\text { Número de ocorrências/ } \\
\text { Total }\end{array}$ & $225 / 253$ & $28 / 253$ \\
\hline Porcentagem & $89 \%$ & $11 \%$ \\
\hline
\end{tabular}

Tabela 01: Distribuição das variantes referentes à concordância verbal em segunda pessoa do singular no corpus analisado

Sabendo que o PA se aproxima mais do português europeu (PE) - por termos realizado pesquisas anteriores acerca da concordância verbal $(\mathrm{CV})$ no português popular de variedades angolanas em terceira pessoa, esse resultado acerca do fenômeno foi previsto e pensado. Os falantes tendem a se aproximar muito do padrão presente nas gramáticas prescritivas de língua portuguesa, mesmo com pouca ou nenhuma escolarização formal; acredita-se que isso acontece devido à colonização portuguesa em países do continente africano e também pelo fim tardio do processo de colonização, a independência de Angola aconteceu em 1975, então a influência portuguesa nos hábitos e na língua dos angolanos ainda é muito expressiva.

Apresentamos o gráfico abaixo para uma melhor visualização do percentual do fenômeno no corpus:

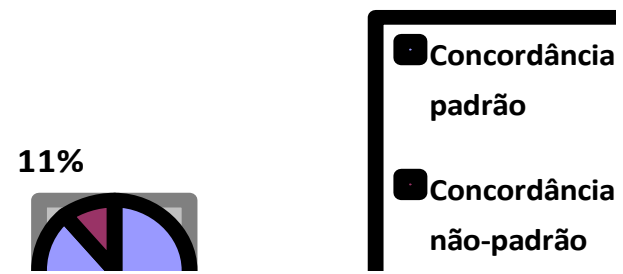

Gráfico 01: Valores percentuais da variável dependente (concordância verbal)

Quanto à variável linguística referente ao uso do pronome de segunda pessoa pelo falante, obtivemos uma frequência muito maior do uso do você em relação ao tu. O uso do você estava presente em 95\% das ocorrências obtidas no corpus. Mesmo não prescrito como pronome de segunda pessoa padrão, o você é comumente observado em contextos informais; podemos atribuir esse valor também à presença da cultura brasileira na sociedade angolana - as novelas brasileiras são assistidas diariamente em Angola, interferindo na cultura e língua dos angolanos. Quando flexionado em segunda pessoa, o pronome você, recebe as mesmas desinências que o pronome de terceira 
pessoa. Na tradição gramatical, o pronome tu é visto como único pronome da segunda pessoa do singular, tendo que concordar em número e gênero em um período. $\mathrm{O}$ potencial variável da língua acaba sendo desconsiderado pelo teor normativo da gramática. Os informantes utilizaram o pronome tu e o você como pronome de segunda pessoa do singular Alguns exemplos obtidos no corpus são apresentados a seguir:

(1) E tu falas com brasileiros, com num sei quê tal e isso.

(2) Tu tens que fazer todo trabalho de casa

(3) se tu não faças, tu no comes e no comes.

(4) Eles dizem tu tens que descer ...vem outra pessoa.

(5) Se tu quiseres descer, pode descer.

(6) e logo você fura lá com afunete.

(7) e aquilo quando você tira com a corda no rio.

(8) Você reclama dentro do táxi e eles te mandam descer[...]

(9) Meu marido me fala, você que vai chegar no seu.

(10) Como é que você vai me agradecer com dois pacotes de sabão.

Há ainda 25 ocorrências em que os falantes usaram de forma peculiar a concordância verbal ao usar o pronome você, pois o pronome você pede a concordância verbal em terceira pessoa e os falantes usaram a concordância verbal padrão de segunda pessoa do singular:

(11) "Ele insistiu sempre: "você só deste cem"

(12) "Não, você não podes gostar de mim"

(13) "Porque você já tens sua namorada.

(14) "você tais a brincar, num quero estudar"

(15) "Essa palavra que você disseste tem que ser assim."

(16) "êpa você vais ficar no caminho e ele vai mêmu no"

As 12 entrevistas foram divididas em dois grupos, o primeiro com falantes de ambos sexos e diferentes faixas etárias que têm como língua materna o português e o segundo com falantes que têm como língua materna alguma língua africana - como o Banto, Kikongo, Kimbundo e outras. A naturalidade dos informantes também foi observada, o curioso é que, quando se trata da concordância verbal com os pronomes tu e você, os falantes do interior tendem a utilizar a concordância verbal com mais frequência, um total de $93 \%$ contra $78 \%$ resultante do obtido nas entrevistas com falantes da capital.

O fator que favoreceu o uso da concordância verbal padrão na segunda pessoa do singular no corpus foi a língua nativa do falante; os dados apontaram para um percentual maior de concordância padrão verbal para os falantes que têm alguma língua nativa africana como L1 - um percentual de $92,9 \%$, que contrasta com $74,5 \%$ para os falantes que tem o Português como L1, o que não era esperado.

Mesmo com a desigualdade social presente em Angola, tanto os falantes do interior quanto os da capital, que tem o Português como língua materna ou não, ainda estão muito próximos do português europeu $(\mathrm{PE})$.

\section{CONSIDERAÇÕES FINAIS (ou Conclusão)}

Evidenciamos com esta pesquisa que o Português de variedades angolanas ainda se encontra muito próximo ao português europeu (PE), a concordância padrão obtida com os pronomes de segunda pessoa tu e você é muito expressiva, totalizando um percentual 
de $89 \%$. Mesmo os resultados obtidos com falantes do interior e que não têm o português como L1, o percentual de concordância se mostra superior ao obtido por falantes da capital e que tem o português como L1. Reforçamos a necessidade de mais pesquisas que tenham como objeto de estudo o português de variedades angolanas.

Vale ressaltar que no corpus os falantes apenas utilizaram o tu e o você como forma de tratamento para segunda pessoa, realizando a concordância verbal padrão de segunda pessoa com o $t u$ e de terceira pessoa com o você, apenas uma ocorrência trouxe um outro pronome "vocemece". Logo, mesmo sendo um estudo do português popular de variedades angolanas, o nível resultante de concordância verbal padrão não se distancia do que poderia ser obtido em uma pesquisa do português culto.

Esta pesquisa aponta para a necessidade de re-aproximação da Língua presente na gramática padrão do português com a língua em seu contexto real, já que a tradição gramatical desconsidera o uso do você como pronome pessoal de $2^{\mathrm{a}}$ pessoa do singular; afastando o falante da sua língua e sustentando as normas e estruturas de uma língua que fora fruto do seu meio e que se tornou apenas reflexo de um falante que não existe mais. É preciso repensar a gramática e o ensino da língua portuguesa.

\section{REFERÊNCIAS}

ARAUJO, Silvana Silva de Farias. A concordância verbal e sua importância para os estudos sobre a formação do português brasileiro. Papia (Brasília), v. 22(1), p. 91-110, 2012.

ARAUJO, Silvana Silva de Farias. A concordância verbal no português falado em Feira de Santana-Ba: sociolinguística e sócio-história do português brasileiro, Tese de Doutorado, Universidade Federal da Bahia, Salvador. Inédita, 2014.

ARAUJO, Silvana Silva de Farias; ALMEIDA, Norma Lucia F. de. O projeto A língua portuguesa no semiárido baiano Fase 3: critérios de constituição e da amostragem do Banco de dados, em R. M. Freitag (Org.). Metodologia de Coleta e Manipulação de Dados em Sociolinguística. São Paulo, Editora Edgard Blücher, p. 27-47, 2014.

BAGNO, Marcos. Português ou brasileiro?: um convite à pesquisa. 2 ed São Paulo Parábola, 2001. P. 123-137.

BECHARA, E. Moderna gramática portuguesa. 37. ed. revista e ampliada. $14^{\mathrm{a}}$ reimpr. - Rio de Janeiro: Lucerna, 2004.

GONÇALVES, C. R. Uma abordagem sociolinguística do uso das formas você, ocê e ce no português. Tese. Doutorado em Linguística - Faculdade de Filosofia, Letras e Ciências Humanas, Universidade de São Paulo, São Paulo, 2008.

LOPES, Célia Regina dos Santos. Retratos da variação entre "você" $e$ "tu" no português do Brasil: sincronia e diacronia In: Português Brasileiro II - contato Linguístico, heterogeneidade e história. Niterói: EDUFF, 2008a, v.2, p. 55-71. 